\title{
POR QUE O
}

COMPARTILHAMENTO

DE dados e tÁ RELEVANTE

PARA SE ALCANÇAR

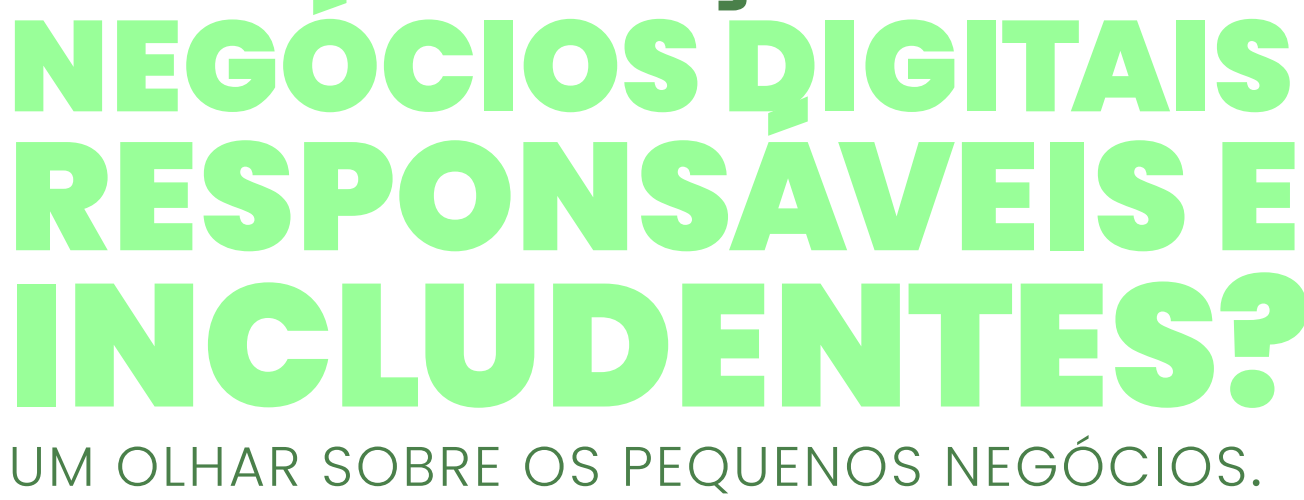

Vinícius Lages

A pandemia revelou com lupa as mazelas de um país desigual, empobrecido e com sérios gaps em relação ao futuro (competências para a economia digital). A incapacidade de adaptação para o trabalho remoto e para a economia digital por parte de milhões de brasileiros, e de pequenos negócios, tem impactado as taxas de desemprego e o encerramento definitivo dos negócios que não foram capazes de se adaptar. Cidadãos desconectados ou inabilitados para serviços digitais nas nuvens limitam sua fluência na oferta de serviços públicos e privados, até mesmo para o recebimento de recursos de programas sociais e auxílio durante a pandemia. As filas nas casas lotéricas e postos de atendimento dos bancos públicos para saque dos auxílios emergenciais foram um testemunho deste atraso tecnológico no acesso a serviços que poderiam facilmente ser digitalizados.

De todo modo, apesar dessas limitações, o distanciamento social decorrente da pandemia ampliou a relação das pessoas com a internet para fins educacionais, profissionais, sociais, assistenciais e econômicos.

Gresceu o entendimento de que o ceesse c̀ internet deixou de ser um serviço de economias desenvolvidas perra se tornar um direíto básico, eomo fornecimento de

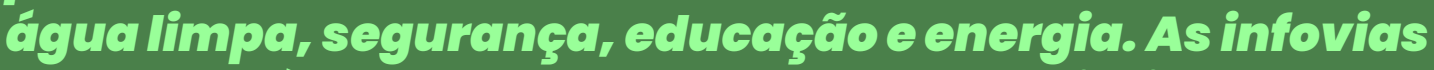
e $\bullet$ acesso à banda larga Grescem como prioridades das demandas de infraestrutura em todo o país.

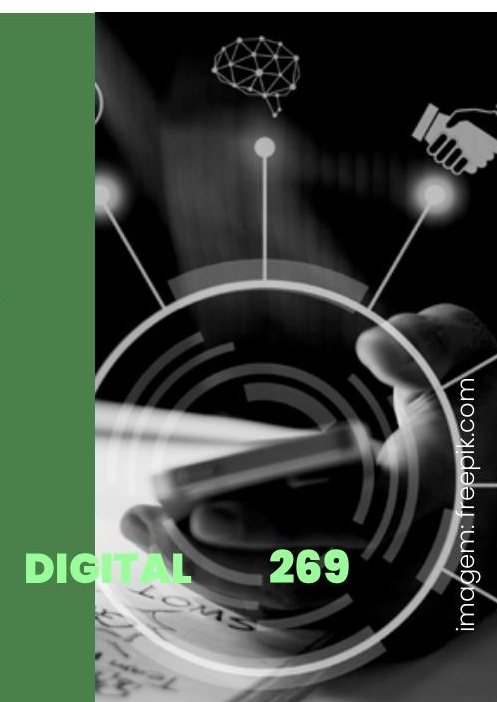


Com o crescimento da rede de $5 \mathrm{G}$ e do loT (internet das coisas) interconectando equipamentos, máquinas, automóveis, eletrodomésticos, processos industriais, ter acesso a dados e à capacidade de analisá-los será ainda mais questão de vida ou morte para os negócios.

Em que pese os efeitos negativos da pandemia sobre a saúde pública e economia, essa crise de escala global tem acelerado um processo de transformação digital que já se colocava de modo incontornável para a maioria dos setores, especialmente para os pequenos negócios.

De uma hora para outra, assistimos atividades econômicas, culturais e mesmo a vida social serem transportadas para o mundo digital através das múltiplas plataformas de e-commerce, streaming de entretenimento, plataformas de ensino e também de trabalho à distância.

Aqueles que de algum modojá haviam feito alguma transformaģão digital ou que se adeptaram meis repidemente têm conseguido amortecer os imperetes de uma economic que sofre - duplo choque de contraģão de ofertu e de demande. a 


\section{Inclusão digitral significa democratizer o acesso às teenologias da informação, permitindo a inserção de todos na sociedade do conhecimento e na economia digital. significa ampliar o acesso aos meios de comunicaçäo digitais, a teenologias da informação, portanto, a harduare, mas sobretudo a saber usar, gerar valor, poder analisar os dados gerados desse uso.}

Para que pequenos negócios possam evoluir em suas jornadas de transformação digital, é preciso que não apenas passem a incorporar tecnologias e processos digitais baseados em dados, mas que evoluam em sua capacidade analítica desses dados. Por razões de limites de capacidade de fazer uma transformação digital em sua plenitude, o acesso a dados relevantes para os pequenos negócios deve ser parte de uma estratégia de dados abertos (open data) que facilita a entrada dos pequenos negócios na economia digital.

O Governo Federal já vem trabalhando uma política de dados abertos e de serviços digitais e grandes corporações, sobretudo na perspectiva de inovação aberta, e tem disponibilizado dados abertos que podem orientar estratégias de negócios de pequenas empresas.

A partir da publicação da Lei de Acesso à Informação (LAI), Lei n 12.5271 sancionada em 18 de novembro de 2011 e regulamentada pelo Decreto $n^{\circ} 7.724$ de 16 de maio de 2012, surgiram dispositivos legais para facilitar o acesso à informação, aos dados governamentais e aos dados de pesquisa científica.

\section{A LAI preconiza que é dever} do Estado garcantir o direito de acesso à informaçáa, devendo ser franqueada de forma ágil, trainsparente, elara e de tấeil compreensão. Esse é um avanço na direçâo de ampliar - acesso a dados que podem gerar oportunidades de negócios e engajamento dos ecossistemas de inovação.

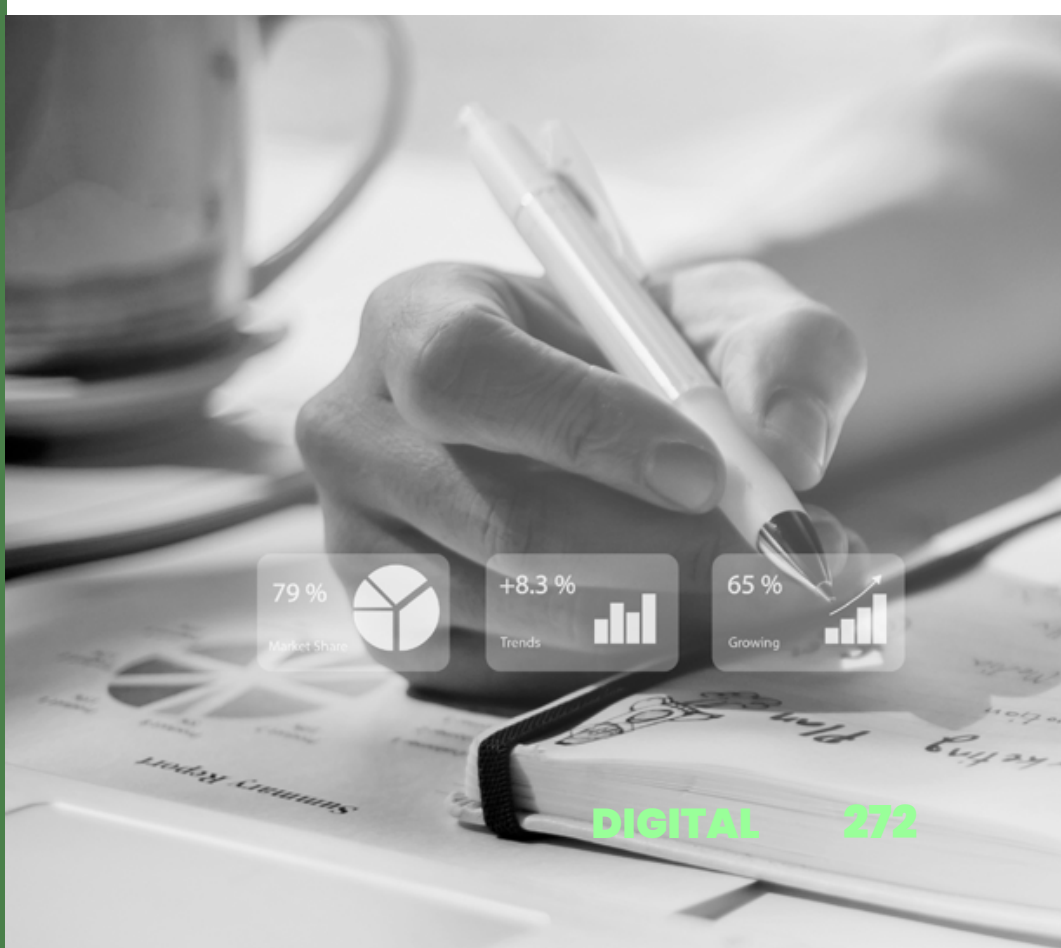


Dados abertos são aqueles disponibilizados ao público (cidadãos, empresas e agentes públicos) e que podem ser utilizados, reutilizados, analisados e compartilhados.

Dados abertos podem ser usados para validar modelos de análise e ajustar algoritmos de inteligência artificial e aprendizagem de máquina. Dados abertos podem ser ativos fundamentais para uma economia mais inclusiva e competitiva, ajudando a encontrar soluções para problemas que afetam toda humanidade nesse mundo transformado pela pandemia e que requer múltiplas formas de cooperação.

Considerando a importância estratégica de ampliar a inclusão digital em um país como o Brasil, tanto para cidadãos quanto para empreendedores de pequenos negócios, é essencial que sejam multiplicadas as iniciativas que habilitem esses agentes para o uso de dados.

Por um lado, o Governo Federal e os diferentes entes federados podem ampliar a utilização de seus serviços digitais e oferecer analytics como um serviço, sobre um conjunto de dados relevantes para seus cidadãos e empresários de pequenos negócios. Atualmente, através do portal Governo Digital1", é possivel acessar cerca de 2.832 serviços digitais, facilitando a vida dos brasileiros. Com uma estratégia de dados abertos associada, é possivel estimular o uso desses dados sobre diversas áreas de interesse coletivo, como, por exemplo, segurança e educação, e através de editais, estimular a inovação aberta, encontrando respostas ou codesenhando soluções com os usuários.

No campo privado, já há algum tempo vemos iniciativas corporativas de inovação aberta baseadas em dados abertos, tanto em circuitos mais fechados, ou seja, com fornecedores ou startups ligados a grandes corporações, ou em iniciativas de impacto social e ambiental, engajando o terceiro setor e estimulando a participação social.

Como abordado ao longo do texto, a transformação digital que assistimos em todo o mundo, em um país como o Brasil, encontra desafios importantes devido aos processos de exclusão que configuram uma das sociedades mais desiguais do mundo.

A inclusc̃o secioprodutiva passa cada vez mais pela inelusão digitud na medida em que o eonhecimentor, a informação edados releventes são edda vez mais acessados pelos meios digitais. Näo se trata apenas de acessar equipementos ou sofutures, ter um smertphone de última geraçăo, mas saber usctr e gerar valor para sua vida pessodl, profissional ou para negócios. É nesse sentido que e cempartilhamento de dades em nuvens públicess e privades deveria ser uma prioridade ders polftices públices. 
Como processo habilitador para e economia digital, para reduzir o gap de novas competências do século XXI, é preciso que cada vez mais o uso de dados e a capacidade analítica sejam fortalecidos. Para uma agência de desenvolvimento de pequenos negócios, como o Sebrae, e que fomenta o empreendedorismo, promover a inclusão digital dos pequenos não apenas promoverá os ajustes nos modelos de negócios requeridos pela economia digital, mas também habilitará empreendedores para a aquisição de competências analíticas essenciais para uma economia cada vez mais baseada em dados e em inteligência assistida.

Muitas corporações do porte da Magazine Luiza, por exemplo, vêm promovendo a inclusão digital de pequenos negócios em sua plataforma de e-commerce. Fruto de uma parceria dessa rede varejista com o Sebrae, já possibilitou a inclusão digital de mais de dezenas de milhares de pequenos negócios.

Na medider em que um pequeno negócio comega a processar e utilizar dados de suas transdģöes neste marketplece, comeģa a amadurecer seu processo de transformaģăo digitel, tornendo-se pouco a pouco orientado por dados (data driven), eixo fundermentel da nova economia digital.
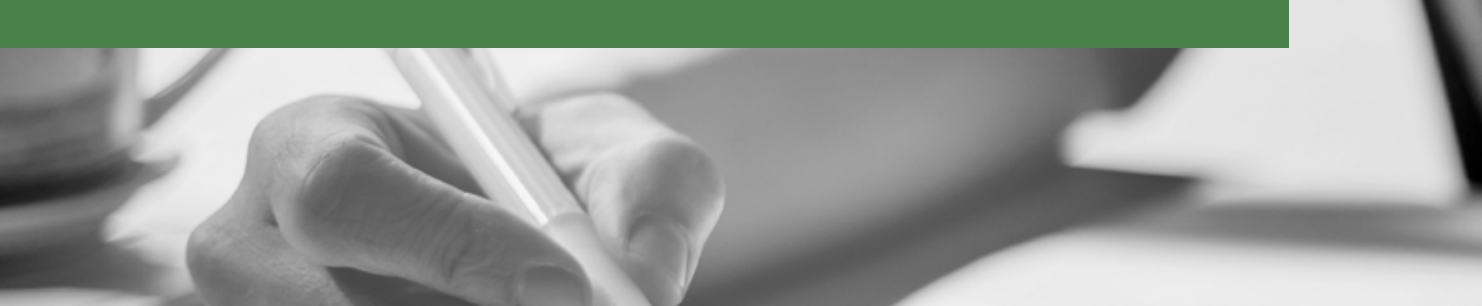

Como discutido, em um país desigual como o Brasil, a inclusão digital torna-se uma ferramenta para facilitar a inclusão de milhões de brasileiros nesta nova economia. No entanto, o maior desafio é habilitar milhões de cidadãos e empreendedores a usarem adequadamente os serviços digitais já existentes e a analisarem dados de modo a poder tornar a análise de dados uma parte integrante de seus modelos de negócios. Isso se faz tanto por estímulos das políticas públicas ou de agências de desenvolvimento como o Sebrae, ou através de iniciativa de inovação baseada em dados abertos, por parte do setor privado. A convergência dessas iniciativas pode acelerar o processo de inclusão digital no país e, mais que isso, acelerar uma transformação digital dos pequenos negócios, base da pirâmide econômica e que hoje ainda estão distantes das competências necessárias para os desafios presentes. 


\section{Vinicius Legges}

Diretor Técnico do Sebrae/AL

Vinícius Lages é Engenheiro Agrônomo, pela Universidade Federal de Alagoas - UFAL, e Doutor em Socioeconomia do Desenvolvimento, pela EHESS - Paris. Foi professor da Universidade Federal de Alagoas (UFAL) e já ocupou cargos de Ministro do Turismo e de Diretor do Sebrae Nacional. Atualmente, é Diretor Técnico do Sebrae Alagoas.

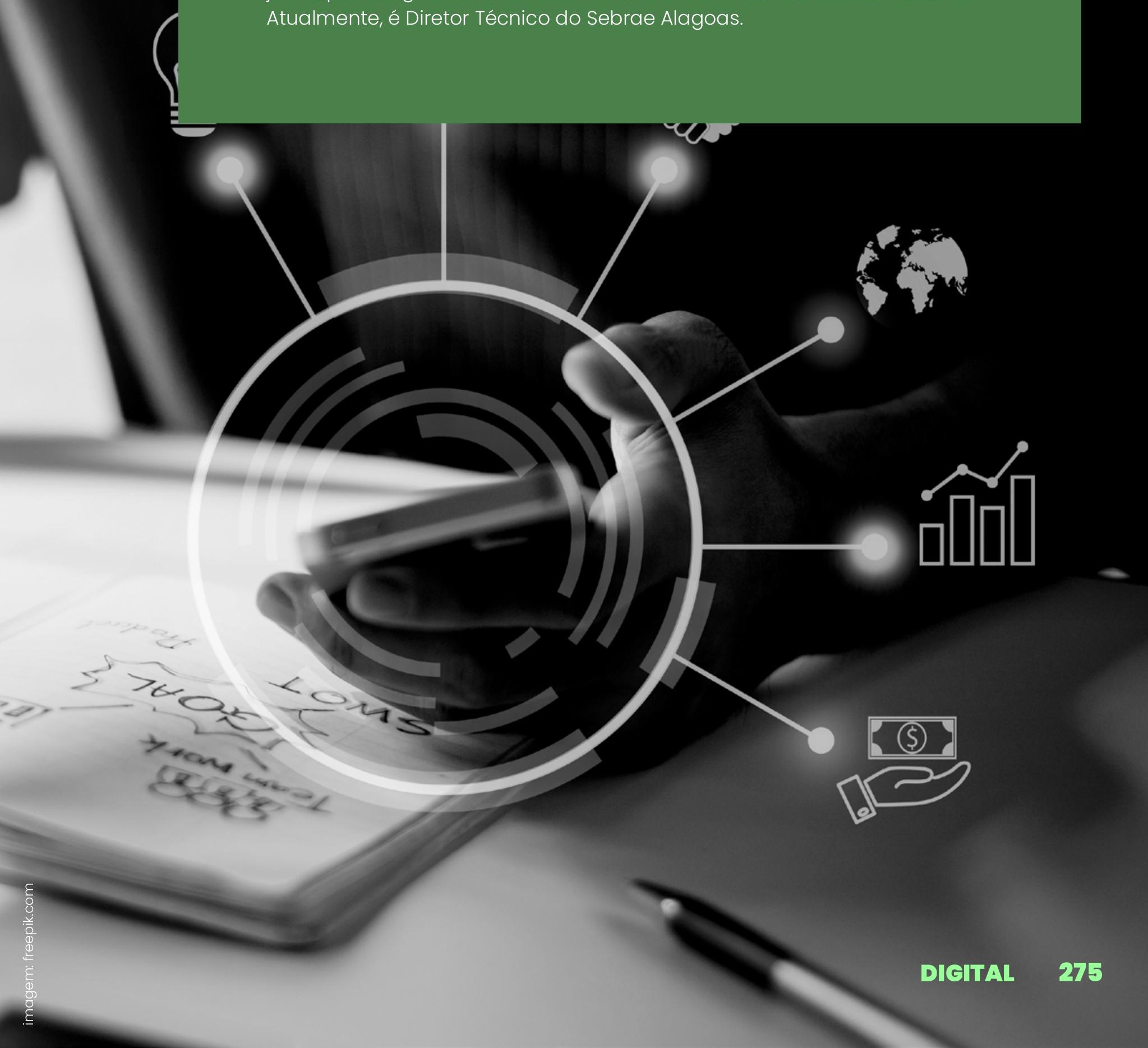




\section{NOTAS REFERÊNGIAS}

1 Disponível em: https://www.gov.br/governodigital/pt-br 